\title{
Kettlebell Exercise as an Alternative to Improve Aerobic Power and Muscle Strength
}

\author{
by \\ Rodrigo Luiz Vancini ${ }^{1}$, Marília Santos Andrade ${ }^{2}$, Weverton Rufo-Tavares ${ }^{1}$, \\ Carla Zimerer ${ }^{1}$, Pantelis Theodoros Nikolaidis ${ }^{3}$, Claudio Andre Barbosa de Lira1,4
}

1- Centro de Educação Física e Desportos (CEFD), Universidade Federal do Espírito Santo (UFES), Vitória/ES, Brazil.

2- Departamento de Fisiologia, Universidade Federal de São Paulo, São Paulo, Brazil.

3- Exercise Physiology Laboratory, Nikaia, Greece.

4- Setor de Fisiologia Humana e do Exercício, Faculdade de Educação Física (FEF), Universidade Federal de Goiás (UFG), Goiânia/GO, Brazil.

Traditionally, maximum oxygen uptake and one-repetition maximum (1RM) are used to assess aerobic power and maximum strength, respectively, and resistance circuit-based training (RCT) is effective in increasing both variables (Muñoz-Martínez et al., 2017). It is important to point that sport performance in many disciplines is related to a high demand of the aerobic/anaerobic metabolism, maximal strength, mechanical power, speed and agility, and the ability to simultaneously train these variables and capacities. These training dynamics and regimen characterize concurrent training.

RCT is the most traditional method of concurrent training and is defined as a single set of several different exercises completed in succession, with little rest exercises. The purpose of RCT is to produce improvements in strength, muscular endurance and aerobic conditioning simultaneously. New trends and strategies of RCT, such as CrossFitTM, promote neuromuscular adaptations (Muñoz-Martínez et al., 2017). However, we would like to expand this view with information regarding kettlebell exercise.

Kettlebell exercise is an alternative to performing functional power and strength exercises (Otto et al., 2012; Williams and Kraemer, 2015), and like RCT, it has been used to improve both aerobic capacity/power and maximal and explosive strength in physical fitness and sport performance facilities (Chan et al., 2018; Eckert and Snarr, 2016; Falatic et al., 2015; Rufo-Tavares et al., 2019). A typical kettlebell session can involve 15-60 seconds of exercise using a dynamic, total-body kettlebell exercise (e.g., twohanded swing, one-handed swing, snatch, squat, clean and press, etc.) followed by 15-60 seconds of rest, repeated for 10-20 minutes (Eckert and Snarr, 2016; Falatic et al., 2015; Rufo-Tavares et al., 2019). As a consequence, kettlebell exercise may elicit cardiovascular, neuromuscular, and metabolic responses sufficient for improvements in strength, aerobic power, and overall physical fitness (Chan et al., 2018; RufoTavares et al., 2019).

\footnotetext{
1 - Centro de Educação Física e Desportos, Universidade Federal do Espírito Santo, Vitória, Brazil.

2 - Departamento de Fisiologia, Universidade Federal de São Paulo, São Paulo, Brazil.

3 - Exercise Physiology Laboratory, Nikaia, Greece.

4 - Setor de Fisiologia Humana e do Exercício, Laboratório de Avaliação do Movimento Humano, Faculdade de Educação Física e Dança, Universidade Federal de Goiás, Goiânia, Brazil.
} 
For these reasons, many strength and conditioning professionals have encouraged the use of kettlebell training as a useful tool in order to improve muscular strength, power and maximum oxygen uptake (Chan et al., 2018; Eckert and Snarr, 2016; Falatic et al., 2015; Rufo-Tavares et al., 2019). For example, Otto et al. (2012) compared the effects of 6 weeks of traditional weightlifting with kettlebell training, in healthy men, on strength (back squat 1RM) and power (vertical jump and power clean 1RM) and showed that both types of activity were effective in increasing these abilities. Falatic et al. (2015) examined the effects of kettlebell training (20 minutes of snatching with 15 seconds of work and rest intervals - 3 days/week for 4 weeks) on aerobic power in female soccer players. They observed an increase of $2.3 \mathrm{~mL} / \mathrm{kg} / \mathrm{min}$, or approximately a $6 \%$ gain, in maximum oxygen uptake and concluded that high-intensity kettlebell exercise could significantly improve aerobic capacity and be used as an alternative strategy to maintain and/or improve cardiovascular fitness.

Finally, a kettlebell practitioner could improve both cardiorespiratory fitness and muscular strength with the same exercise protocol as in RCT. Furthermore, considering that traditional strength training devices (barbells) and exercise facilities (gyms) could be expensive and keep beginners away, kettlebell exercise may be a more affordable and accessible strength and aerobic training alternative to increase and maintain physical fitness related to cardiorespiratory health and power and strength performance, with low cost (for coach and/or practitioners) because it requires less equipment and restricted physical space. However, it needs to be guided by trained professionals. For novice users, a familiarization period is suggested to augment exercise security and proficiency. Therefore, kettlebell exercise has the potential to be used as a form and in the context of RCT.

\section{References}

Chan M, MacInnis MJ, Koch S, MacLeod KE, Lohse KR, Gallo ME, Sheel AW, Koehle MS. Cardiopulmonary Demand of 16-kg Kettlebell Snatches in Simulated Girevoy Sport. J Strength Cond Res, 2018 [ahead of print]

Eckert RM, Snarr RL. Kettlebell Training: A Brief Review. J Sport Hum Perform, 2016; 4: 1-10

Falatic JA, Plato PA, Holder C, Finch D, Han K, Cisar CJ. Effects of Kettlebell Training on Aerobic Capacity. J Strength Cond Res, 2015; 29: 1943-1947

Muñoz-Martínez FA, Rubio-Arias JÁ, Ramos-Campo DJ, Alcaraz PE. Effectiveness of Resistance CircuitBased Training for Maximum Oxygen Uptake and Upper-Body One-Repetition Maximum Improvements: A Systematic Review and Meta-Analysis. Sports Med, 2017; 47: 2553-2568

Otto WH, Coburn JW, Brown LE, Spiering BA. Effects of Weightlifting vs. Kettlebell Training on Vertical Jump, Strength, and Body Composition. J Strength Cond Res, 2012; 26: 1199-1202

Rufo-Tavares W, Lira CAB, Zimerer C, Andrade MS, Leopoldo AS, Perez AJ, Vancini RL. Short-term detraining is not enough to reduce positive adaptations of kettlebell training on power and strength variables in physically active women. Gazz Med Ital - Archivio per le Scienze Mediche, 2019; 178: 56-65

Williams BM, Kraemer RR. Comparison of Cardiorespiratory and Metabolic Responses in Kettlebell HighIntensity Interval Training Versus Sprint Interval Cycling. J Strength Cond Res, 2015; 29: 3317-3325

\section{Acknowledgements}

CABL had a fellowship from the Coordenação de Aperfeiçoamento de Pessoal de Ensino Superior, Programa Nacional de Pós-Doutorado (CAPES/PNPD - Coordination for the Improvement of Higher Education Personnel, National Postdoctoral Program, Brazil). RLV is a productivity fellow at the Fundação de Amparo à Pesquisa e Inovação do Espírito Santo (FAPES) agency (Edital № 18/2018 - Bolsa Pesquisador Capixaba).

\section{Corresponding author: \\ Rodrigo Luiz Vancini}

Centro de Educação Física e Desportos (CEFD), Universidade Federal do Espírito Santo (UFES), Campus Universitário; Av. Fernando Ferrari, 514; CEP: 29075810; Goiabeiras, Vitória-ES, Brasil;

Phone: +55-27-40092624/40092636; E-mail: rodrigoluizvancini@gmail.com 